\title{
About an Intracranial Aneurysm Rupture During Delivery
}

\author{
Ibrahim Assoumane ${ }^{1,2,0}$ Loucif Houari ${ }^{2}$ Abdelhalim Morsli ${ }^{2}$ \\ ${ }^{1}$ Department of Neurosurgery, Reference Hospital Maradi, Niamey, \\ Niamey, Republic of Niger \\ 2Department of Neurosurgery, Neurosurgery Unit of Bab El Oued \\ Teaching Hospital, Alger, Algeria

\begin{abstract}
Address for correspondence Ibrahim Assoumane, MD, Department of Neurosurgery, Reference Hospital Maradi, Niamey, Niamey 227, Republic of Niger (e-mail: as_ibrah2006@yahoo.fr, assoubrahim18@gmail.com).
\end{abstract}

Indian J Neurosurg 2019;8:52-54

\begin{abstract}
Keywords

- aneurysm

- pregnancy

- delivery

- endovascular

The rupture of an intracranial aneurysm is rare during pregnancy and exceptional during delivery. When it occurs, the prognosis of two lives is engaged. We are reporting a case of a 41-year-old patient presenting with a subarachnoid hemorrhage during labor. After extraction of healthy baby through cesarian section, radiological investigations permitted to diagnose a ruptured right carotid-ophthalmic aneurysm. The patient benefited from a selective aneurysm's exclusion by occlusion using Guglielmi detachable coils through an endovascular approach using catheterization. The immediate outcome was favorable.
\end{abstract}

\section{Introduction}

The subarachnoid hemorrhage due to intracranial aneurysm rupture during pregnancy is rare, with an incidence between 0.01 and $0.05 \%,{ }^{1}$ and occurs exceptionally during delivery. Nowadays, most of the reported cases are clinical case reports. In case of aneurysm rupture, physicians are facing challenges where the vital prognosis of two persons is engaged.

We are reporting the case of a patient aged of 41 years who presented an aneurysm rupture during delivery. The patient was operated and a cesarian section permitted the extraction of a healthy newborn. This was performed before the aneurysm exclusion by endovascular approach. Here, we are discussing clinic, pathophysiologic, and therapeutic aspects of aneurysm rupture during delivery period.

\section{Observation}

Authors are reporting the case of a 41-year-old patient, who experienced her fourth pregnancy, and three previous parity; the last child was 4 years old and the patient was a bearer of 38 weeks of amenorrhea pregnancy. The patient reported intermittent headaches with helmet shaped since 3 days. She consulted a neurology unit where a brain CT scan was performed without abnormalities. At 38 weeks of amenorrhea, she was admitted to the obstetric unit for labor at $5 \mathrm{~cm}$ cervical dilatation. The labor was augmented with syntocinon (oxytocin) to ease the delivery. She had painful uterine contractions, and a few minutes later, intense headache was followed by convulsion and a short loss of consciousness. The patient was driven to the operation theater for a cesarian section. The surgical team attempted a lumbar puncture three times for a spinal anesthesia which was showing a bloody backflow that permitted one to suspect a subarachnoid hemorrhage. The decision was made to perform general anesthesia for the cesarian section that allowed extracting a male child with a 10 Apgar score. After postsurgical wake up, the patient was transferred to the neurosurgery unit for specialized advice. Clinical examination retrieved a conscious patient with $15 / 15$ on the Glasgow coma scale with a meningeal syndrome consisting of headache, photophobia, phonophobia, and neck stiffness without neurologic impairment. She was classified as World Federation of Neurosurgical Societies (WFNS) 1, Hunt and Hess 1. A brain MRI with angiographic sequence was performed, highlighting a right carotid-ophthalmic aneurysm (-Fig. 1). To have better characteristics of the lesion, a cerebral angiography was performed, showing a right carotid-ophthalmic aneurysm that bled ( $\boldsymbol{- \text { Fig. }}$ 2). The patient benefited from an endovascular treatment consisting of embolization of the carotid-ophthalmic aneurysm with coils ( - Fig. 3). The immediate outcome after embolization was favorable and the patient was released with a regular follow-up during external consultations.
DOI https://doi.org/

$10.1055 / \mathrm{s}-0039-3403456$ ISSN 2277-954X.
(C2020 Neurological Surgeons' Society of India
License terms

()(1) $\Theta$ 


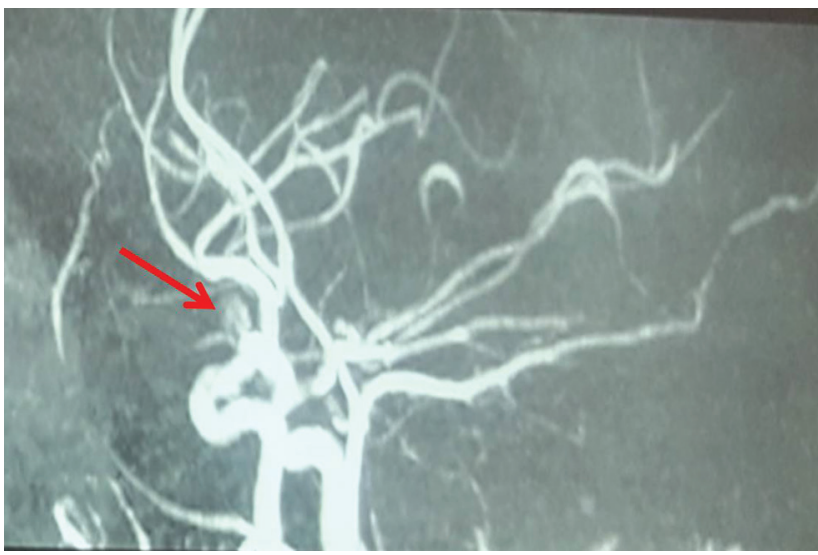

Fig. 1 Angio MRI showing the carotid-ophthalmic aneurysm (red arrow). MRI, magnetic resonance imaging.

\section{Discussion}

The incidence of ruptured intracranial aneurysm during pregnancy is difficult to evaluate because most of the data vary from 3 to 10 for 100,000 pregnancies. ${ }^{2}$ Multiple factors were involved as fostering the rupture during pregnancy; physiologic hemodynamic variations that occur during pregnancy will lead to vascular stress and risk of formation, growth, and rupture of an intracranial aneurysm. Those vascular modifications are influenced by estrogens and progesterone, endothelial growth factors, which increase during pregnancy. ${ }^{3}$ Adjustments of the maternal body made for an increase of cardiac flow and plasmatic volume, which is maximal at the third trimester of pregnancy, reported by many authors as the rupture time $e^{4,5}$ respectively $73 \%$ and $55 \%$. In a literature review, Barbarite et $\mathrm{al}^{3}$ reported $78 \%$ of aneurysms rupture during the third trimester
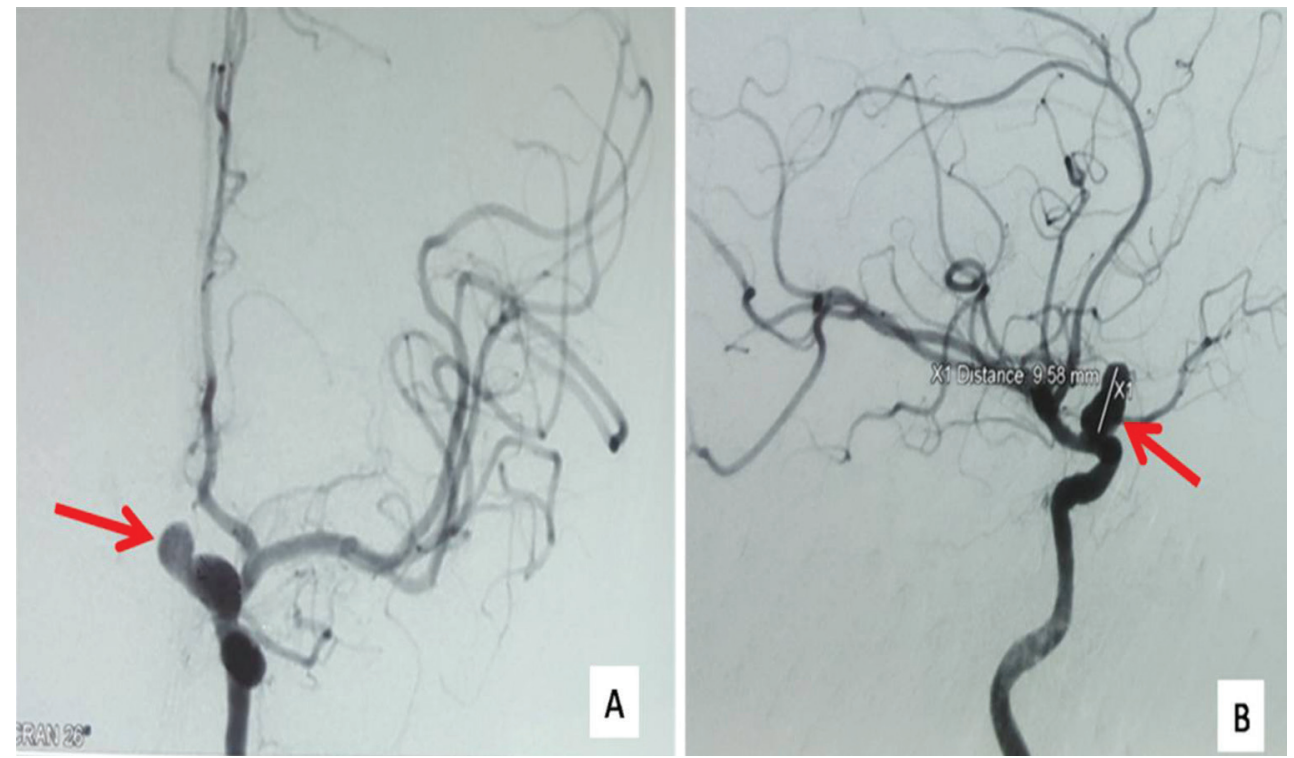

Fig. 2 Right ICA angiography showing the ophthalmic aneurysm. (A) Anteroposterior view. (B) Sagittal view. ICA, internal carotid artery.
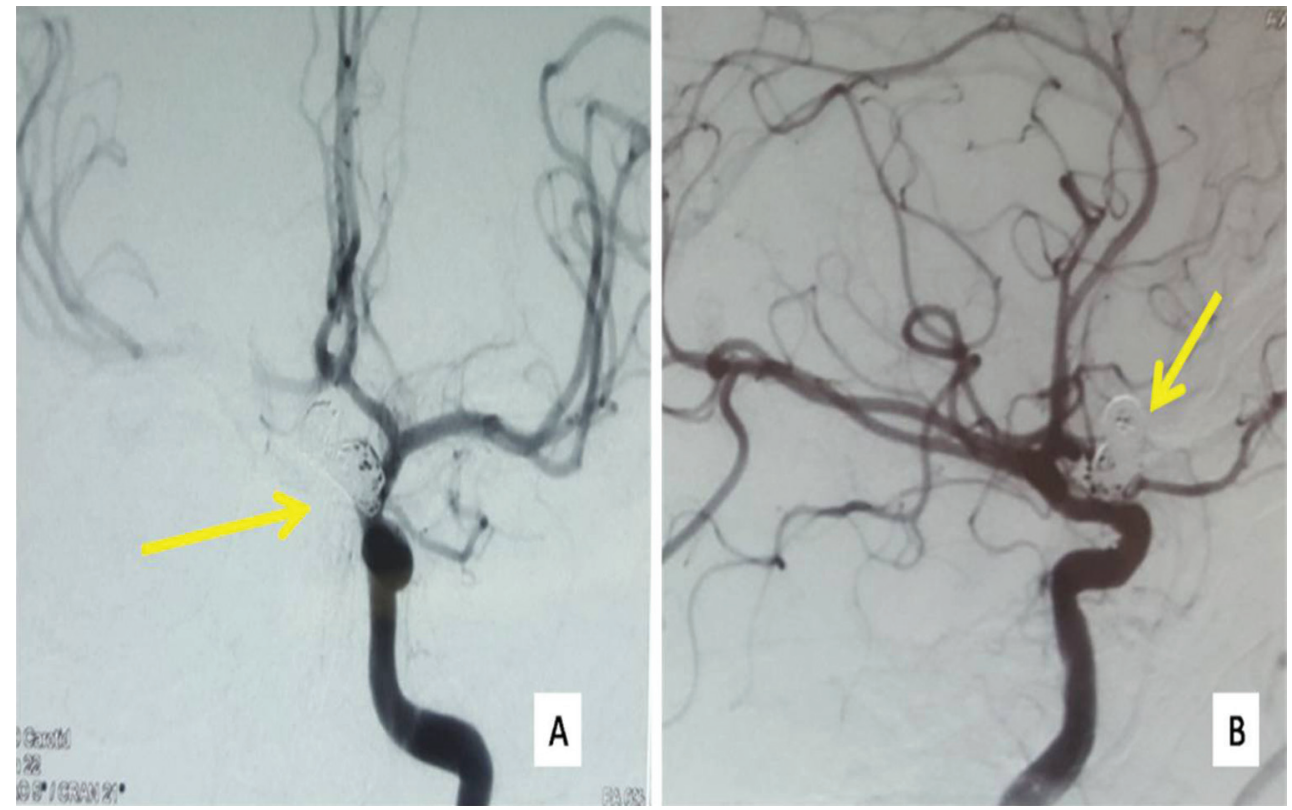

Fig. 3 Postembolization angiography showing the embolized aneurysm (arrows). 
pregnancy among which only $7.14 \%$ during labor. The lumbar puncture for locoregional anesthesia is a fostering factor for the aneurysm rupture because of the loss of cerebrospinal fluid and increase in the inner wall vascular pressure. ${ }^{6}$ The localization of aneurysm during pregnancy is different from the general population. Half (50\%) of the ruptured aneurysms are located at the level of internal carotid artery against $39.1 \%$ at the level of anterior communicating artery. There are multiple aneurysms in $20 \%$ of cases. The differential diagnosis is eclampsia crisis which can delay proper care. ${ }^{2}$ In their literature review, Barbarite et $\mathrm{al}^{3}$ reported that endovascular approach was mostly compared with clipping, respectively $47.7 \%$ against $36.4 \%$. Endovascular treatment is harmless and allows a short hospitalization, but can be dangerous because of the heparin therapy that follows if a cesarian section is planned after. It can also be dangerous for the baby because of radiations during the procedure if delivery has not yet been performed. ${ }^{3}$ Diagnosis of aneurysm rupture was suspected during delivery for our patient, which allowed the obstetrician to extract the child and begin studies to underpin the diagnosis. It is true that the baby is on the safe side if delivery occurs before aneurysm treatment because of anesthesia risk, maternal hemodynamic variations due to aneurysm rupture such as vasospasm and hypoxia, dehydration, and acidosis due to low uterine perfusion. ${ }^{7}$ All these precautions enable good results for the baby and easy anesthetic and neurosurgical management of the patient during the surgery. For pregnant ladies having intracranial aneurysms, $84.2 \%$ of surgical teams prefer delivery through cesarian section ${ }^{3}$; normal delivery seems to be inappropriate because of the efforts made during contraction. ${ }^{8}$ The mortality rate can be high, ranging between 13 and 35\% for the mother, and 7\% and 25\% for the fetus. ${ }^{9}$ It is the third cause of nonobstetrical maternal death in United Kingdom, with a 5 to $12 \%$ rate. ${ }^{10}$

\section{Conclusion}

Intracranial aneurysm rupture during pregnancy is a delicate issue to manage because the prognosis of two individual lives is engaged at the same time. It requires a multidisciplinary consultation between obstetrician, neurosurgeon, neuroradiologist, and anesthesiologist, to decide on the timing and the first-line treatment procedure.

\section{Conflict of Interest}

None declared.

\section{References}

1 Kizilkilic O, Albayram S, Adaletli I, et al. Endovascular treatment of ruptured intracranial aneurysms during pregnancy: report of three cases. Arch Gynecol Obstet 2003;268(4):325-328

2 Kataoka H, Miyoshi T, Neki R, Yoshimatsu J, Ishibashi-Ueda H, Iihara K. Subarachnoid hemorrhage from intracranial aneurysms during pregnancy and the puerperium. Neurol Med Chir (Tokyo) 2013;53(8):549-554

3 Barbarite E, Hussain S, Dellarole A, Elhammady MS, Peterson E. The management of intracranial aneurysms during pregnancy: a systematic review. Turk Neurosurg 2016;26(4):465-474

4 Robba C, Bacigaluppi S, Bragazzi NL, et al. Aneurysmal subarachnoid hemorrhage in pregnancy-case series, review, and pooled data analysis. World Neurosurg 2016;88:383-398

5 Tarnaris A, Haliasos N, Watkins LD. Endovascular treatment of ruptured intracranial aneurysms during pregnancy: is this the best way forward? Case report and review of the literature. Clin Neurol Neurosurg 2012;114(6):703-706

6 Böttiger BW, Diezel G. Acute intracranial subarachnoid hemorrhage following repeated spinal anesthesia [article in German]. Anaesthesist 1992;41(3):152-157

7 Kriplani A, Relan S, Misra NK, Mehta VS, Takkar D. Ruptured intracranial aneurysm complicating pregnancy. Int J Gynaecol Obstet 1995;48(2):201-206

8 Brunken M, Kehler U, Fiehler J, Leppien A, Eckert B. Coiling vs. clipping: hospital stay and procedure time in intracranial aneurysm treatment [article in German]. RoFo Fortschr Geb Rontgenstr Nuklearmed 2009;181(10):989-995

9 Roman H, Descargues G, Lopes M, et al. Subarachnoid hemorrhage due to cerebral aneurysmal rupture during pregnancy. Acta Obstet Gynecol Scand 2004;83(4):330-334

10 de Swiet M. Maternal mortality: confidential enquiries into maternal deaths in the United Kingdom. Am J Obstet Gynecol 2000;182(4):760-766 